\title{
Investigating the Effects of Online Research Skills Instructions: A Quasi-Experimental Study in Grade 8
}

\author{
Hoda Kain $^{1.2^{*}} \quad$ Nehme Safa ${ }^{2}$ \\ 1. High School Teacher, the Makassed Philanthropic Society, Saida-Lebanon \\ 2. Faculty of Educational Sciences, Saint-Joseph University of Beirut
}

\begin{abstract}
This article reports on a part of a larger mixed-methods, quasi-experimental study which investigated the effect of a comprehensive model of online source- use on developing online research skills and lessening copy-paste trend in the writing pieces of Grade 8 ESL students $(n=172)$ in three private schools in Saida, Lebanon. Eight teachers were randomly assigned into experimental and control conditions along with their respective classes. Five of these teachers implemented a ten-session intervention. The main researcher collected pre and post data on online research and comprehension assessment tool (revised-ORCA). Supported with current research and informed by the principles of the social- cognitive, socio-cultural, and the new literacies theories, statistical analyses revealed that the experimental group outperformed the control group, showing higher score gains from pre-test to post-test on an overall score of revised ORCA as well as on its subskills. It was also noted that the contribution of the intervention on the scores of communicate ideas responsibly was almost twice the effect on the rest of subskills. Theoretical and pedagogical implications generated from this study were discussed. Recommendations for school policies and further research were also provided.
\end{abstract}

Keywords: online research skills, copy-paste, middle school, ESL/EFL

DOI: $10.7176 / \mathrm{JEP} / 11-33-11$

Publication date: November $30^{\text {th }} 2020$

\section{Introduction}

Writing from sources has always been fundamental in academic fields. It has emerged as a crucial asset in the workplace and academic communities where employees need to be competent in writing proposals, literary criticism, reports, among others (Howard et al., 2010; Solomon, 2018). In fact, this literacy skill has always been challenging even to native speakers due to the need for sufficient knowledge and competency to integrate reading and writing skills while writing from different sources. Thus, this integration requires teachers to design specific tasks that emphasize much practice of reading, summarizing, paraphrasing, evaluating, synthesizing, and resourceciting skills (Cho et al., 2015; Evering \& Mooreman, 2012; Grabe \& Zhang, 2013; Solomon, 2018). Failure to achieve these skills results in students' tendency to copy words, phrases, or even whole written passages from the original source into their own writing assignments (Cumming et al., 2018; Howard \& Davies, 2009), a phenomenon labelled as plagiarism.

With the advent of digital literacy, the process of writing from sources has become more complicated. Evidence exists that shows differences between online and offline reading comprehension. For example, Leu et al. (2005) found out little or no significant correlation $(r=.103, p=.352)$ between online reading and offline reading-where the former was measured using a valid and reliable instrument (ORCA), and the latter was measured using a common standardized traditional reading test (Touchstone Associates, 2004). Coiro and Dobler (2007) used think-aloud protocol to explore the strategies employed by Grade 6 students while carrying on an online reading comprehension task. They found out that even though these students employed strategies similar to those of offline reading comprehension, they used other complex strategies in terms of prior knowledge of the domain, unique inferential reasoning, and rapid self-regulated strategies. Specifically, authors of print source present their informational texts in a way that is "fixed in content and structure" (Malloy et al., 2010, p. 224). So, readers of print sources follow a fixed path-specifically, a linear one. This means that they can: (a) read any section based on purpose and in any order; (b) skim and scan sections according to interests; and (c) make use of sections provided by the author such as the glossary, text headings, tables, and graphs. In contrast, authors of online texts present their work in a miscellaneous manner, which might mislead online readers who have to follow a non-linear path to effectively comprehend these texts before properly incorporating the retrieved information into their written assignments. Such changes have led researchers and composition theorists to conclude that even though the today's students might have very good practices on the Internet, they are not good online readers since they lack the skills of new literacies (e.g., Castek et al., 2015;Coiro, 2007). Accordingly, these researchers and composition theorists have raised a call for a new understanding of literacy in the Internet era which must include literacy of the Internet environment as well (Castek, 2017; Castek et al., 2015; Coiro \& Dobler, 2007; Howard \& Davies, 2009; Schwartz, 2016).

This has prompted many researchers to assume the significance of integrating effective instructional practices as part of the curriculum so that students could face the challenges and acquire the skills of online reading which 
include, but are not limited to, the skills of locating sources within the Internet, reading websites and webpages, and using self-regulated strategies when distracted by hyperlinks (Chen, 2010). As a result, many scholars have attempted to define the skills of new literacies required for an effective reading and writing from online sources, where they have framed online reading as a web-based inquiry which involves the skills and strategies to generate a research question, locate needed information, evaluate such information, and properly make use of it through synthesizing it into original product. At the international level, policy initiatives regarding the appropriate use of online sources were taken, where online research skills and copy-paste avoidance were emphasized in the national standards in some countries such as Australia, Canada, and USA (Leu et al., 2014). In the context of Lebanon, the concept of students' lack of online research skills and its direct link to the increase of copy-paste from Internet sources were highlighted in some research studies. However, this link was neither emphasized nor investigated since most relevant studies in this field remained descriptive in nature both at university (Bacha \& Bahous, 2010) and school Level (e.g., Bacha et al., 2012; Fidaoui et al., 2010).

\section{Theoretical Framework and Review of Literature}

Two lines of research were fundamental to set the framework of the present study: research on new literacies of online research and comprehension and research on Internet plagiarism. However, the line of research pertaining to online plagiarism was narrowed to indicate textual borrowing from Internet sources in a form of copy and paste ideas directly into own piece of writing. The relationship between online research skills and copy-paste trend were mirrored and confirmed in the theoretical background that informed the present study.

In fact, this study was informed by several theories and theoretical models which are suitable for application in classroom contexts. It has foundations in the views of Vygotsky's (1978) socio-cultural theory, Bandura's (1986) social cognitive theory, and in the perspectives of the new literacies theory of online reading comprehension (e.g., Coiro \& Dobler, 2007). Previous findings emphasized the effectiveness of instructional scaffolding, the role of more able person, and the impact of social environment to alter learning, all of which form the notions of Vygotsky, the theorist whose work informed the present study. Vygotsky's principles are mainly reflected in the reciprocal teaching, the effective approach used to design the IRT model. Research findings further emphasized the positive relation between modeling and achievement. Most importantly, strong evidence exists in literature regarding the interaction between the individual, behavior, and environment-all of which form the basis of the socio-cognitive theory of Bandura. As for new literacies theory, theorists in this field still consider it as very early to define a theory of new literacies due to the consistent and continuous change in the field. Recently, they have framed online reading as a problem-based inquiry that involves new strategies and skills. Thus, rather than using online reading, they coined the term online research and comprehension skills (e.g., Castek et al., 2015). In this paper, the terms online reading, online reading and comprehension, online research and comprehension skills, and online research skills are used interchangeably.

\subsection{The Internet Era and a New Shift in Literacy}

Literacy experts and researchers have increasingly grown interest in the development of literacy within the classroom context (e.g., Castek, 2008; Çetin \& Halisdemir, 2019), especially that today's generations have a strong tendency to consider Internet as the main source of information (Leu et al., 2005; Putman, 2013). Their results have indicated that the Internet is actually presenting today's students with new complexities that prevent them from adequate interaction with texts in this medium where new technologies always emerge (Coiro \& Moore, 2012; Goldman, Braasch, et al., 2012). These complexities, as assumed by many researchers and composition theorists, have enabled these students, including high school students, to produce copy-paste written work easily (e.g., Callahan, 2006; Howard \& Davies, 2009; Rothschild, 2009), which has consequently led to a decline in the academic writing and the learning process and has jeopardized future career as well (Howard et al., 2010). This assumption has led the authors in the present study to track a line of inquiry which assumed an existing relationship between the lack of online research skills and copy-paste trend.

A thorough examination of existing research showed that a growing body of research documented students' challenges in terms of employing copy-paste avoidance techniques while writing from Internet sources retrieved from the Internet (Howard \& Davies, 2009; Leu et al., 2004; Robbins, 2010) and highlighted that pedagogical interventions that would help students face these challenges should teach students the aforementioned skills of online research as well as provide explicit instructions on copy-paste avoidance (Evering \& Moorman, 2012; Houth, 2017; Howard \& Davies, 2009). Empirical research regarding the effectiveness of explicit instructions to reduce occurrences of textual plagiarism through promoting online research skills and copy-paste avoidance was carried out in many studies in the context of universities ( Evering \& Moorman; Houth, 2017; Howard et al., 2010) and schools (Walter, 2008; Williamson \& McGregor, 2011). Some of these studies showed the significance of intervening with a workshop on developing online research skills and reducing the frequency of copy-paste from Internet sources (Houth, 2017), integrating instructional practices that employ explicit instructions and scaffolding (Evering \& Moorman, 2012), or employing a group inquiry project (Lee et al., 2016). Others (e.g., Williamson \& 
McGregor, 2011) investigated the issue through exploring teachers' and students' perceptions regarding the effectiveness of their instructions, where their findings indicated the effectiveness of an instructional practice that provided explicit teaching and modeling of online research skills as well as citing skills as compared to intervening with an intervention that emphasized individual practice only.

In the context of exploring the issue in depth in ESL (English as a Second Language) classrooms, review articles cited several studies which were in line with the aforementioned findings (e.g., Pecorari \& Petric, 2014). Most of these studies either provided empirical evidence or recommended that the issue of copy-paste trend could be curtailed by an instructional practice that provided explicit teaching on online source use and referencing. Most of these studies considered that issues learners of English as Second language and English as First Language encounter while writing from online sources are somehow similar. It is worth to note that most of these studies revealed a growing concern that integration of the skills of new literacy should start at an early stage of the students' education. In fact, advocates of new literacies of online research and comprehension specified primary classroom levels as a must to start teaching these skills (e.g., Forzani \& Leu, 2012).

Such concern has been mirrored in Lebanon, the context of the present study, as well. Despite the awareness that researchers in the Lebanese context have shown regarding both the extent of the issue at university levels (Bacha \& Bahous, 2010; McCabe et al., 2008) and at school levels (Bacha et al., 2012) and regarding the appropriate pedagogical approaches to address it (Esseili, 2019; Fidaoui et al., 2010), most of their studies-except for the study of Esseili (2019) have focused on academic integrity in general, with no or little emphasis on online research skills and on the variable of copy-paste trend (e.g., Bacha et al., 2012; McCabe et al., 2008). Interestingly, these skills were emphasized in Lebanon's National Educational Technology Strategic Plan which was launched in 2011 (The Ministry of Education and Higher Education, 2012). The plan set goals to be achieved by 2017. For example, Goal 1.5 in this plan emphasizes the ability to conduct research, organize data, solve problems, produce original work, communicate ideas, utilize print and non-print information ethically, use different types of ICTs to gain understanding, and use print and non-print sources to locate, evaluate, and synthesize. Although the goals of this plan reflect the significance of these skills and are aligned with international standards, teachers have not received adequate training yet (Awada \& Diab, 2016; Fidaoui et al., 2010).

\subsection{Pedagogical Interventions to Develop Online Research Skills and Copy-Paste Avoidance}

In the field of developing the skills of reading and writing from Internet sources, many approaches emerged. One of these was the Internet Reciprocal Teaching (IRT). This model was developed by Professor Leu and his colleagues in 2007 (Malloy et al., 2007) based on the Reciprocal Teaching Model (RT) of Palinscar and Brown (1984).

\subsubsection{Internet Reciprocal Teaching (IRT)}

The IRT model was the result of a 3-year project conducted at middle schools in the United States by the Teaching Internet Comprehension to Adolescents team (TICA), and it was funded by the institute of Education Sciences U.S. Department of education. The research team sought not only to develop reading comprehension strategies for online and print texts, but they also intended to increase middle school students' engagement and academic development, especially for those who were at risk. The original RT model is based on the four strategies of making predictions, asking questions, clarifying, and summarizing, whereas the IRT model employs the strategies of asking questions, locating relevant information, synthesizing, evaluating, and communicating ideas to others using an online tool or platform. The RT model is limited to small groups, whereas the IRT can be implemented with all students with different levels. However, these models employ many similar strategies such as utilizing explicit teaching and modeling while scaffolding students' learning within the zone of proximal development (ZPD), a main component in Vygotsky's theory which aims to help students gradually attain their actual learning abilities; both models emphasize the role of peer support.

The final IRT model was designed into three phases "that differ in degrees of strategy complexity, level of student responsibility for teaching and modeling for others, and degrees of independent inquiry and use" (Castek, 2017 , p. 212). The three phases of instructions address the skills that online readers need to become proficient in, with an emphasis of gradual release of responsibility. Phase 1 includes mainly teacher-led discussion with a focus on basic skills of Internet use such as identifying a search engine and basics of web browser. Throughout this phase, teachers use high levels of scaffolding techniques, employ group work skills, and create an engaging environment by inviting them to share their knowledge (Castek et al., 2015). Phase II of the IRT model includes exchange of online research and comprehension strategies in reciprocal groups between teachers and students and students and their peers. Gradually, IRT lessons present students with problem-based learning linked to students' curriculum. Teachers model instructions explicitly through moderate scaffolding techniques and gradually decrease their role and talk to let students engage with the problem. Phase III of the IRT model is designed as an inquiry process through which students practice all the skills of online reading, with the teacher assuming the role of a facilitator.

IRT provides teachers with mechanics and strategies to support students throughout the process of reading 
and writing from online sources by providing different instructional scaffolds such as explicit teaching of the skills, guided practice, peer-to-peer discussion, and individual practice. As evident, it employs the strategies of teaching reading and writing processes together. Empirical evidence regarding the effectiveness of the teaching of reading and writing together was noted in literature (e.g., Katz et al., 2013). Research findings showed that teaching reading and writing together supports the development of these two literacy skills. Graham, Liu, et al. (2017) conducted a meta-analysis in which they examined 38 experimental studies from preschool through high school to explore the extent and significance of reading-writing integrative models. Results indicated that such integration can develop both reading and writing performance. As for reading growth, 18 out of every 20 studies produced a high effect size at the post-test $(E S=0.33)$, "resulting in meaningful and significant improvements on a composite measures of overall reading performance" (p. 287). Castek (2017) considered that "recognizing that reading and writing are interrelated processes is an essential part of online reading comprehension" (p. 214).

IRT was proven to be very effective in intact classroom settings. Some of the studies were implemented in lower and upper middle schools and employed mixed methods quasi-experimental design (Castek, 2008; Robbins, 2010), whereas others employed quasi-experimental design (Ali, 2017; Kingsley, 2011) to explore its effectiveness in Grade 5 In her dissertation thesis, Kingsley (2011) conducted a quasi-experimental study at a middle school $(n=418)$ in the United States, where teachers were randomly assigned into experimental and control conditions and were provided with 13 online reading comprehension lessons. After controlling for the preexisting differences between the experimental and control group on pre-tests of two standardized tests of traditional reading comprehension (ELA Proficiency Test and SRI) and on online reading comprehension assessment (revisedORCA), she used ANCOVA analysis to eliminate the effects of the previously mentioned covariates; results indicated a greater statistical difference $(\mathrm{p}<.05)$ in favor of the experimental group. Additional analysis was conducted to scrutinize the effect of the intervention on the individual skills of locating, evaluating, and synthesizing. Using MANCOVA, analysis revealed significant differences between the experimental and the control group, in favor of the former, on the skills of locating and synthesizing $(p<.05)$. Ali $(2017)$ experimented with the IRT intervention in the context of EFL in Egypt. Using a quasi-experimental method, she examined the effect of IRT on developing the online reading comprehension skills of Grade 10 EFL students in Tanta during the first term of the academic year. She also investigated whether a relationship existed between self-efficacy and online reading comprehension. Independent- samples $t$-test analysis revealed significant gains on online research skills at post-test in favor of the experimental group $(t=-12.95, p<.05)$.

In short, results from the first line of research (online research skills) revealed that lack of online research skills need to be addressed through integrating reciprocal teaching within the classroom context and adopting several scaffolding instructions with gradual release of responsibility from the teacher to students (e.g., Castek, 2008; Kingsley, 2011). In facts, adopting these strategies is very significant to the process of learning from the theoretical perspectives of social cognitive theory and socio-cultural theory whose assumptions informed the present study. Tracking the literature regarding the second line of research (online plagiarism in terms of copypaste trend) led the authors of the present study to detect enough evidence regarding the significance of adopting a proactive pedagogy which emphasized teaching online research and comprehension skills to reduce copy-paste behavior (e.g., Houth, 2017; Howard \& Davies, 2009). Recent approaches abroad showed the benefits of providing instructions on online research and comprehension skills and copy-paste reduction as early as middle or high school (Houth, 2017; Lee et al., 2016).

However, based on the review conducted in the present study, most studies and practices in Lebanon, except for the study of Esseili (2019), are still lagging behind in this area. Most of these studies focused on teachers' and students' perceptions of this issue (Bacha \& Bahous, 2010)- even though many recommendations were made to adopt an instructional practice that teaches the skills of online research and helps students reduce copy-paste trend (Bahous et al., 2012; Fidaoui, et al., 2010). This research gap, supported by research on the development of literacy in the Internet age and on Internet plagiarism, was addressed in the present study which investigated whether the IRT intervention would be effective in the Lebanese context, as compared to traditional teaching of online research skills. Thus, intervening with the IRT model in the context of Grade 8 classroom would respond to these recommendations and provide a valuable instructional practice for educators who seek to teach students how to properly write from Internet sources in the EFL (English as a Foreign Language) and ESL classes. This study would also contribute to narrowing the gap between theory and practice in the educational research in EFL/ESL Lebanese context, which teachers find inappropriate to their ongoing practices (Esseili, 2011, as cited in Awada \& Diab, 2016). Most importantly, the results of the present study would contribute to the wide international discussion with regards to finding pedagogical practices to develop students' online research skills and copy-paste avoidance techniques. To this end, the authors of the present study hypothesized that Grade 8 ESL students who receive lessons designed on the IRT model, which promotes online research skills and copy-paste reduction techniques, will significantly demonstrate high scores on online research skills assessment than do other students who receive traditional teaching 


\section{Purpose of the Study}

This article reported on a part of a larger mixed-methods, quasi-experimental study designed to investigate the effect of intervening with a comprehensive instructional practice, based on IRT model, to develop the skills of online research and lessen the occurrences of copy-paste trend. In light of the above mentioned gap, this article reported on the results of a quasi-experimental design which was employed to test the effectiveness of IRT intervention by scrutinizing pre-test and post-test measures of online research skills in an intact Grade 8 ESL classroom environment. Specifically, this part of the study was designed to investigate whether explicit teaching and practicing of online research skills by experimental group students would make significant developments in the performance of this group on these skills and yield less occurrences of copy-paste, as compared to the performance of students in the control group who received traditional instructions on these skills. The research question that this part of the study sought to answer was: How do lessons, designed on IRT, which promotes online research skills and lessens copy-paste occurrences from Internet sources, affect the performance of Grade 8 ESL students on online research skills assessment?

\section{Methodology}

This section of the article describes the methodology used in carrying out this part of the original study.

\subsection{Research Design}

The part of the study reported in this article adopted the quasi-experimental pre-test /post-test design with nonequivalent control group (Creswell \& Plano Clark, 2018) to investigate the effect of instructional lessons, designed based on the IRT model, on students' performance on online research skills and copy-paste reduction assessment.

\subsection{Site and Selection of Schools}

The study was conducted in the south of Lebanon at three private co-educational middle and high schools, which were purposefully selected in terms of schedule flexibility, Internet connection, and co-educational school systems. To ensure confidentiality, each school was given a pseudonym (School A, B, and C). In general, the three schools share common characteristics which made them a good fit in this study. English is used as a medium for other subjects such as mathematics and sciences and taught as a separate subject as well. Information technology (IT) teachers emphasize the technical use of Internet and computer such as presentations, file management, website making, drawing skills, etc., but they do not teach online research skills. The three schools had the required Internet speed available at the computer lab, which is only a two-minute walk from the class and has one computer per student.

\subsection{Participants and Sampling Technique}

The sample size for the present study consisted of 172 Grade 8 ESL students ( $n=172 ; 86$ females and 86 males) aged between 13 and 14 years old along with their 8 teachers. Most of them came from the same geographical area, had similar socioeconomic status, and were frequent Internet users. In all, there were 118 students in the experimental classes ( 2 sections per school) and 57 in the control classes (one at each school). Prior to the intervention, the authors of the present study conducted an informal interview with teachers and found out that teachers at the three sites were comparable in terms of working experience, education, technology use, and knowledge of students' Internet practices. The purpose was also to identify to whom the study findings might generalize (Graham \& Harris, 2014). All of them were females, with a minimum experience that ranged between 5-15 years. Interview analysis revealed that these teachers perceived themselves as having sufficient computer and Internet skills for personal and instructional purposes. They demonstrated awareness of their students' weaknesses in reading and writing from Internet sources, which, according to them, led students to insert exact sentences and words from online sources into writing assignments. Surprisingly, they complained about lack of in-service training as a factor that prevented them from designing instructional practices to guide students on how to develop the skills of reading and writing from Internet sources and decrease the occurrences of copy-paste. This complaint was echoed in the work of many researchers (Howard \& Davies, 2009; Ma et al. 2006; Walter, 2008).

All teachers' and students' names were coded to maintain confidentiality. Teachers along with their intact sections were randomly assigned to treatment conditions since participants were present in intact classes (Gay et al., 2012). Teachers' names were written on index cards, folded, and then put in a box. In School A and B, the first two names were selected for the experimental condition. However, in School C, where there were only two teachers distributed among the three classes, the first name was selected for the experimental condition. Luckily, the name of teacher who was teaching sections A and B at this school was first picked up.

\subsection{Measures}

The authors administered two instruments: The Internet Usage Survey and Revised ORCA. The two instruments underwent a pilot testing, and, accordingly, necessary revisions were made in terms of question directions, duration, 
and words (e.g., Ismail et al., 2018). The validity and reliability of these instruments were credited in previous research; however, they were examined for the sake of the present study since some items were modified to fit in the new context.

4.4.1 Student Internet Usage Survey

For the purpose of this part of the study, this self-reported tool was used to measure initial differences between the experimental and control group on variables that would affect the results other than the IRT intervention. Specifically, the survey comprised 3 factors: (a) Internet Use, which measured the frequency of Internet use at school and home; (b) Internet Skills or Efficacy, which measured the efficacy of students to perform an online research task; and (c) Internet Attitude, which measured students' attitudes towards factors that would lead to copy-paste from Internet sources. An expert in the field checked this instrument for content validity. Reliability of items that measured Internet use and Internet skills was calculated using Cronbach's alpha and revealed an $\alpha=.63$ and $\alpha=.854$, respectively, which indicated an adequate internal consistency of items that measured the Internet use and highly adequate internal consistency of items that measured Internet skills (Hinton et al., 2004). Reliability of Internet attitude was supported with findings in literature (Lee et al., 2016; Sisti, 2007).

4.4.2 Pre-test/Post-test Online Research and Comprehension Assessment (Revised ORCA)

In the present study, Revised ORCA measured the effectiveness of the IRT model of instruction on the increase in students' scores of online research and comprehension skills from pre-test to post-test conditions and examined the differences in gain of scores between those who received the intervention and those who did not. Castek (2008) designed the original version based on the perspectives of new literacies (Leu et al., 2004) to obtain precise data on the students' performance on the 5 skills of new literacies listed as follows :(1) ask questions, (2) locate online information, (3) evaluate such information, (4) synthesize information from multiple sources, and (5) communicate ideas to other audiences using online tools. ORCA tool included a rating scale for each of these skills, which students had to demonstrate through taking the pre-test/post-test ORCA authentic informational tests. In the present study, the five tasks originally designed by Castek to measure the five skills were modified into two long missions where each of these missions included two tasks, with two steps each. Another essential revision was made on the tasks and rubrics that measured "communicate ideas", which was replaced with "communicate ideas responsibly" to measure copy-paste occurrences in students' written work. Revisions were also made to the score for each level scale to obtain a unified equal level of scoring scale (0-4) for each subscale of ORCA. A specialist in the field checked the instrument for content validity. The reliability of the overall revised ORCA instrument used in the present study was calculated at .71, which indicated a high level of internal-consistency among items (Hinton et al., 2004).

4.4.3 Pre-test/Post-test ORCA Authentic Informational Tests

Revised ORCA was used to measure the performance on a two-mission test titled "Kids Need Sleep." The concept was chosen from the students' science curriculum and was selected after conversing with the science and English language arts teachers. Each mission had two tasks. The questions in each task asked students to: (1) locate the required source using simpler to more complex searching skills, (2) look for the main reasons kids need to sleep, (3) look for ways kids could sleep without medicine, (4) evaluate the required source in terms of accuracy and trustworthiness by finding at least another site which has similar information to confirm their answers, and (5) communicate the summarized ideas using their own words and citing the sources properly using an online platform. Content and readability levels of online websites and pages were validated by two science and Language arts teachers.

\subsection{Intervention lessons on Online Research Skills}

As mentioned earlier, the intervention lessons used in the present study were designed by Kingsley (2011) according to the three phases of the IRT model: (a) Phase I, teacher modeling; (b) Phase II, guided practice; and (c) Phase III, independent inquiry. The revised lessons were: (1) Nuts and Bolts, a 45 minute session with a set of activities that taught students the basic skills needed to navigate and use the Internet; (2) Questioning, a twosession lesson that taught students how to build a research question using the topic, theme, and focus flow chart of Eagleton and Dobler (2007); (3) Searching, a two-session lesson that included strategies for searching the web such as using the keywords needed to be typed in Google bar to look for the required data; (4) Critical Evaluation, a two-session lesson that focused on teaching the critical evaluation skill; and (5) Synthesizing Using Own Words and Communicating Ideas Responsibly, a three-session lesson that taught students how to paraphrase ideas from more than one source using own words and citing references using APA citation wizard, an online platform, to generate a good end reference .

\subsection{Treatment Fidelity}

The researcher tried to determine if teachers in the experimental group implemented instructions as agreed upon and as planned (Smith et al., 2007). Before the intervention, the researcher made sure all teachers received adequate training. During the intervention, the researcher used Robbins' (2010) checklist to check the proper 
implementation of the intervention in terms of (a) IT tools, (b) skills being taught, (c) time provided for students' guided and individual practice, and (d) strategies used by teachers.

\subsection{Control Group}

During the duration of the intervention, the control groups at the three sites had equal access to technology and used the computer lab within the same time-frame designated to the experimental groups to accomplish activities related to their units such as exploring websites, getting information, etc. However, they were not instructed on the skills of online research through the lessons of the IRT intervention.

\section{Results}

After preparing data on Excel program, data were cleaned for accuracy and prepared by deleting missing cases using listwise deletion. All files were then imported to the Statistical Package Social Sciences (SPSS) version 23 to run descriptive and inferential statistical analyses.

Independent- samples $t$-tests were run on the two pre-assessment measures to determine if both the control and the experimental groups had potential differences prior to the intervention implementation and to ensure that the procedure of randomly assigning teachers along with their respective classes to experimental and control conditions had not yielded prior differences. Results of the data obtained from the Independent-samples $t$-tests with $95 \%$ confidence interval (CI) level indicated no statistically significant difference in mean scores between the two groups on measures of Internet use for the experimental $(M=1.47, S D=0.51)$ and control group $(M=$ $1.43, S D=0.50) ; t(170)=.43, \rho=.67(\rho>.05)$, CI $[-.13, .20]$. Similarly, there was no significant difference in scores of Internet attitudes between the experimental $(M=-3.18, S D=1.45)$ and control group $(M=-3.44, S D=$ $1.33) ; t(170)=1.15, \rho=.25$, CI $[-.19, .73]$. However, results indicated a statistically significant difference $(\rho<.05)$ in scores of Internet skills /self-efficacy, where the experimental group reported a mean score $(M=3.68, S D=$ $0.92)$ higher than that of the control $(M=3.36, S D=1.02) ; t(170)=2.04, \rho=.04(\rho<.05)$, CI [.01, .63]. Likewise, a statistically significant difference was noted in scores of revised ORCA, where the experimental group reported a mean score $(M=1.58, S D=0.31)$ higher than the mean score of the control group $(M=1.45, S D=0.31) ; t(170)$ $=2.68, \rho=.008, \mathrm{CI}[.04, .24]$.Such differences on Internet skills /self-efficacy and revised ORCA were accounted for by including them both as covariates in further statistical analyses. Following is a detailed analysis of the research question.

\subsection{Effect of Scripted Lessons on the Overall Scores of Online Research and Comprehension Skills and Copy-Paste Reduction as well as on the Individual Skill Score}

The authors hypothesized that lessons based on The IRT model would significantly improve the overall as well as the individual skill scores of students in the experimental on revised ORCA, as compared to the control group. Analysis of Covariance (ANCOVA) was run to examine whether the intervention caused significant gains between the total scores of the pre-test and post-test. The independent variable was the instructional scripted lessons, and the dependent variable was revised ORCA post-test scores. In this test analysis, the pre-test scores of revised ORCA and Internet skills/self-efficacy were used as covariates to remove their preexisting differences. Before continuing with ANCOVA test, preliminary checks were run on the assumptions of reliability of the covariate, linearity, and homogeneity of variance to confirm these assumptions. Levene's Test of Equality of Error Variances $(F=.348, p=.556)$ revealed that the assumption of equality of variance was not violated $(p>.05)$. ANCOVA test result is presented in Table 5.1.

Table 5.1 Analysis of Covariance (ANCOVA) of Post-test ORCA Scores as a Function of the IRT Intervention

\begin{tabular}{lcccccc}
\hline Source & $S S$ & $D f$ & $M S$ & $F$ & $P$ & $\eta_{p}{ }^{2}$ \\
\hline Corrected Model & 92.573 & 3 & 30.858 & 173.417 & .000 & .756 \\
Intercept & 16.101 & 1 & 16.101 & 90.487 & .000 & .350 \\
Internet skills pre-test Mean & 1.226 & 1 & 1.226 & 6.893 & .009 & .039 \\
Revised ORCA pre-test Mean & .664 & 1 & .664 & 3.733 & .055 & .022 \\
Group & 79.254 & 1 & 79.254 & 445.401 & .000 & .726 \\
Error & 29.894 & 168 & .178 & & & \\
Total & 1425.693 & 172 & & & \\
Corrected Total & 122.466 & 171 & & & \\
\hline Note. $S S$, Type III sum of squares; $M S=$ mean square; $\eta_{p}{ }^{2}=$ partial eta squared; covariates, pre-test mean scores \\
of revised ORCA and Internet skills /self-efficacy; Dependent variable, revised ORCA post-test mean scores)
\end{tabular}

After adjusting for the pre-test scores, results indicated a statistically significant difference between the experimental and control groups on post-test scores of revised ORCA, $F(1,168)=445.401, \rho<.05$, partial eta square $\left(\eta_{p}{ }^{2}=.726\right)$. Thus, the effect of the intervention was statistically significant $(\rho<.05)$. Partial eta squared showed a large effect size (Cohen, 1988, as cited in Aryadoust \& Raquel, 2019), indicating that the IRT intervention accounted for around $72.6 \%$ of the variance in the ORCA post-test. The partial eta squared of the pre- 
test scores of the Internet skills/self-efficacy $\left(\eta_{p}{ }^{2}=.039\right)$ and ORCA pre-test scores $\left(\eta_{p}{ }^{2}=022\right)$ showed that, these parameters, though statistically significant (Internet skills, $\rho=.009<.05)$ or approaching significant (ORCA pre , $p=.055$ ), accounted, respectively, for only $3.9 \%$ and $2.2 \%$ of the variance in the ORCA post-test, indicating a small effect size (Tabachnik \& Fidell, 2013, p.55, as cited in Aryadoust \& Raquel, 2019). Thus, as revealed in Table 5.1 (Group), Grade 8 ESL students who received lessons on online research and comprehension skills and copy-paste reduction obtained higher mean scores than students who received traditional teaching. Further, examining the estimated marginal means (see Table 5.2) would provide a good interpretation of the effectiveness of the intervention on the performance of online research skills and copy-paste reduction. As evident, the estimated marginal mean score on revised ORCA post-test for the experimental group was almost twice the mean score of the control (3.23 and 1.72, respectively).

Table 5. 2 Unadjusted and Estimated Marginal Means on the Revised ORCA Post-test Scores

\begin{tabular}{lll} 
& Experimental & Control \\
\hline Unadjusted means & 3.24 & 1.68 \\
Estimated marginal means & 3.23 & 1.72 \\
\hline
\end{tabular}

Note. Covariates appearing in the model are evaluated at the following values: Internet skills/self-efficacy mean score at pre-test $=3.5789$, revised ORCA mean score at pre-test $=1.5401$; estimated marginal means provided the adjusted means on the revised ORCA post-test for the experimental and control groups after statistically removing the effect of the two covariates (pre-test scores of revised ORCA and Internet skills/self-efficacy (Pallant, 2011).

MANCOVA was run to examine the effect of the IRT on each of the subscales of revised ORCA. It is worth noting that having a large sample size helped assume normality and equality of variance (Pallant, 2011). Table 5.3, Table 5.4, and Table 5.5 demonstrate the outcome of MANCOVA and the significant effect of the intervention. Table 5. 3 Unadjusted and Estimated Marginal Mean Scores on the revised ORCA Components by Condition, controlling for Pre-test Mean Scores of Revised ORCA and Internet Skills

\begin{tabular}{llll}
\hline & & Experimental & Control \\
\hline Evaluate & Unadjusted means & 2.35 & 0.57 \\
Synthesize & Estimated marginal means & 2.34 & 0.61 \\
& Unadjusted means & 3.48 & 1.99 \\
& Estimated marginal means & 3.46 & 2.03 \\
Locate & & & 3.01 \\
& Unadjusted means & 3.88 & 3.05 \\
Communicate Responsibly & Estimated marginal means & 3.86 & 0.84 \\
\hline
\end{tabular}

Table 5.4 shows the results of the Multivariate test where the global effect on the linear combination of all dependent variables is evaluated. The revised ORCA pre-test mean scores did explain a tiny amount of variance in the model (the partial eta squared $=3 \%$ ), but it did not reach statistical significance. Although the effect of Internet skills /self-efficacy was statistically significant $(\rho=.013)$, it only explained $7.4 \%$ of the variance in the model, indicating a small effect. However, the experimental intervention explained $82 \%$ of the variance $(\eta p 2=$ $0.815, \rho<.001)$.

Table 5. 4 Results of The Multivariate MANCOVA Test

\begin{tabular}{lccccc}
\hline Effect & $F$ & Hypothesis $d f$ & Error $d f$ & $\rho$ & $\eta_{p}{ }^{2}$ \\
\hline Internet Skills Pre-test mean score & 3.288 & 4.000 & 165.000 & .013 & .074 \\
Revised ORCA pre-test mean score & 1.288 & 4.000 & 165.000 & .277 & .030 \\
Experimental intervention & 181.635 & 4.000 & 165.000 & .000 & .815 \\
\hline
\end{tabular}

Table 5.5 displays the effect of the IRT intervention on each of the dependent variables in the MANCOVA model as well as the effect of the two covariates. The effect of the pre-test mean score of Internet skills /selfefficacy (covariate) was statistically significant only on "locate" and "communicate ideas responsibly". However, the contribution of this covariate to the variances of those variables was around $4 \%\left(\eta_{p}{ }^{2}=.043\right)$, indicating a small effect size following Cohen's (1988, as cited in Aryadoust \& Raquel, 2019) guidelines. As for pre-test mean score of revised ORCA, results showed that the effect of this covariate was not statistically significant on each of the dependent variables $(\rho>.05)$. Examining the effect of the IRT intervention showed a statistically significant result on each of the dependent variables $(\rho<.001)$. The contribution of the IRT intervention to the variances of those variables was large (above 40\%), especially for "communicate ideas responsibly," which revealed approximately twice the effect $(80 \%)$. 
Table 5. 5 MANCOVA Tests of Between-Subjects Effects

\begin{tabular}{|c|c|c|c|c|c|c|c|}
\hline & & $S S$ & $D f$ & $M S$ & $F$ & $P$ & $\eta_{p}^{2}$ \\
\hline \multirow{4}{*}{$\begin{array}{l}\text { Internet skills pre-test } \\
\text { mean score }\end{array}$} & Evaluate & 1.519 & 1 & 1.519 & 2.505 & .115 & .015 \\
\hline & Synthesize & .812 & 1 & .812 & 2.315 & .130 & .014 \\
\hline & Locate & 1.408 & 1 & 1.408 & 7.510 & .007 & .043 \\
\hline & Communicate ideas responsibly & 1.733 & 1 & 1.733 & 7.483 & .007 & .043 \\
\hline \multirow{4}{*}{$\begin{array}{l}\text { Revised ORCA pre- } \\
\text { test mean score }\end{array}$} & Evaluate & .214 & 1 & 214 & .353 & .553 & .002 \\
\hline & Synthesize & 1.014 & 1 & 1.014 & 2.890 & .091 & .017 \\
\hline & Locate & .594 & 1 & .594 & 3.169 & .077 & .019 \\
\hline & Communicate ideas responsibly & .686 & 1 & .686 & 2.961 & .087 & .017 \\
\hline \multirow{4}{*}{$\begin{array}{l}\text { Experimental } \\
\text { intervention }\end{array}$} & Evaluate & 104.543 & 1 & 104.543 & 172.429 & .000 & .507 \\
\hline & Synthesize & 71.818 & 1 & 71.818 & 204.732 & .000 & .549 \\
\hline & Locate & 23.093 & 1 & 23.093 & 123.202 & .000 & .423 \\
\hline & Communicate ideas responsibly & 157.080 & 1 & 157.080 & 678.335 & .000 & .801 \\
\hline
\end{tabular}

\subsection{Validity of Scoring the Revised ORCA Instrument}

The accuracy of scoring the revised ORCA instrument was obtained through Intra-class correlation (ICC) using a two- way random-effects model. Selecting both raters randomly "from a larger population of raters with similar characteristics" would serve the purpose of generalizing the reliability of findings "to any raters who possess the same characteristics as the selected raters in the reliability study" (Koo \& Li, 2016, p. 157). ICC estimates and their 95\% confidence intervals levels were calculated using SPSS statistical package version 23. Results were as follows: (a) locate, pre-test ICC $=.968$; post-test ICC $=.893$; (b) synthesize, pre-test ICC $=.869$; post-test ICC $=.977 ;$ (c) evaluate, pre-test ICC $=.826$; post-test ICC $=.897 ;$ (d) communicate ideas responsibly, pre-test ICC $=.800$; post-test ICC $=.983$. These results ranged between "good", "good to excellent", and "excellent" as interpreted by Koo and $\mathrm{Li}(2016)$.

\section{Discussion and interpretation}

As stated earlier, the results reported in this article were part of a larger mixed-methods, quasi-experimental study, and they were related to the research question which investigated the effectiveness of the IRT model in developing the performance on online research skills and copy-paste reduction, as measured by revised ORCA. It also investigated the effectiveness of the model on developing each individual skill. This section discusses these results, relates them to earlier relevant research and theories in the field, and provides some interpretations.

Results revealed that student participants in the experimental group developed proficiency with the skills of online research as compared to those in the control group after controlling for the effect of the two covariates ( pretest scores of revised ORCA and Internet skills). The effect of the intervention on the linear combination of the four revised ORCA components and on the individual skill was promising in terms of statistical significance and noticeable large effect size. Interestingly, the contribution of the intervention on the communicate ideas responsibly was approximately twice the effect on the rest of subskills. This indicated that the IRT intervention positively affected each subskill of online research; however, the noticeable effect on developing "communicate ideas responsibly" indicated a decrease in the occurrences of copy-paste behavior. This would imply that a classroom instructional practice that integrates the skills of online research within the teaching unit and that employs unique strategies of modeling, scaffolding, and peer-to-peer support to scaffold students' learning is essential to tackle an issue of concern to all academic institutions and future employers, considering the critical learning need of these skills as discussed earlier in this paper. Results imply that teachers would need an in-service training to create a positive class environment, develop knowledge of online research skills and copy-paste avoidance techniques, and design instructional practices that build on their students' needs (Fidaoui et al., 2010; Kingsley, 2011).

Going back to existing research, findings of the present study were in line with the findings of previous research (Ali, 2017; Castek, 2008; Kingsley, 2011) regarding developing the performance of the overall scores of online research and comprehension skills. Castek (2008) and Kingsley (2011) intervened with IRT model as an instructional practice to develop online research skills in the context of Grade 5 language arts class in the United States, whereas as Ali (2017) intervened with IRT model in the context of Grade 10 EFL in Tanta, Egypt. In the present study as well as in Kingsley's (2011), preliminary analyses showed initial differences between the experimental and control group, and which were controlled for using ANCOVA. One possible explanation of such findings obtained in the present study and those of the aforementioned studies could be attributed to the design and process of the intervention lessons which scaffold students' learning by breaking down the instructions into the three IRT phases: (a) explicit teaching and modeling, (b) guided-practice, and (c) independent inquiry practice.

Interestingly, these results were also in line with a study by Lee et al. (2016) in terms of the positive effect of employing the aforementioned strategies to develop not only online research skills but also copy-paste 
avoidance techniques in a middle school context. The researchers investigated the effect of their UPCC program by comparing the results of two class cohorts that worked on the inquiry project, but only one of these cohorts received UPCC, which focused on teaching online research skills through employing explicit teaching, modeling, and group work. UPCC pedagogy is designed by Lee et al., 2016 and refers to : "understanding plagiarism, learning about paraphrasing and related skills, generating proper citations with an online citation tool, and doing originally check with an online tool" ( Lee et al., 2016, p.1). Similar to this study, the researchers attributed the decrease in the percentages of group that demonstrated plagiarism behavior to the explicit instructions of online research skills and to the peer-peer support. However, unlike the present study, where the performance of each student was measured using a scoring rubric, Lee et al. (2016) measured the domains of the UPCC program through group project score and checked originality of written work using an online site. Another study conducted by Houth (2017) recorded similar gains among university students who received explicit teaching on online research skills and copy-paste avoidance. However, the focus was on the outcome where the researchers measured the occurrences of plagiarism using a rubric and Turnitin reports. This finding was also reflected in the claims of Howard and Davies (2009).

In reference to the results of subskills analysis, findings were comparable to those revealed in Ali (2017) in terms of all subskills of online research and to those revealed in Castek (2008), Dwyer (2010), and Kingsley (2011) in terms of "locate" and "synthesize" subskills. Findings of another study by Kuiper et al. (2008) had different results in terms of some subskills. For example, Grade 5 students in the study of Kuiper et al. (2008) were not able to demonstrate consistent ability in locating relevant information and writing from these sources. Such differences between the present study and those of Kuiper et al. (2008) could be attributed to the lessons of the IRT model which were designed in three phases and moved from simpler to more complex skills using explicit and reciprocal teaching. These results, therefore, would suggest that IRT model would have accelerated students' ability in the experimental group in the present study as well as in other studies to develop these skills (e.g., Castek, 2008; Dwyer, 2010; Kingsley, 2011; Robbins, 2010).

As for the effect on students' ability to synthesize, positive gains were noted in the present study as well as in existing literature (Castek, 2008; Dwyer, 2010, Kingsley, 2010; Lee et al., 2016). However, Dwyer (2010) noted that that fifth/sixth class cohort students in her study showed better abilities to write from online sources using own words than did third/fourth cohort students. Accordingly, Dwyer (2010) suggested that the acquisition of the synthesis skills have critical demands which are developmental in nature. Such justifications might in turn provide a valid logical support why eighth graders in the present study demonstrated similar gain to those in Lee et al.'s (2016) study but better gains than those in Dwyer's. Similar justification might also account for the differences that were noticed in the results of critical evaluation between the present study and the other studies that exist in literature. In the present study, Grade 8 students in the experimental group demonstrated better gains in scores of critical evaluation, as compared to other studies (e.g., Dwyer, 2010; Kingsley, 2011). Dwyer (2010) asserted that critical evaluation skills are "developmental in nature," and thus "may be difficult to develop with children" (Dwyer, 2010, p. 387), whereas Kingsley (2011) believed that providing students with more explicit instructions and giving them extra time to practice these skills would help them develop their performance. Such findings would indicate that differences in the age group and cognitive level of students play a significant role in accelerating the development of synthesis and critical thinking skills.

The last subskill of revised ORCA tool was "communicate ideas responsibly," which measured the occurrences of copy-paste trend from the Internet. Most studies that employed IRT model, to the knowledge of the main researcher of the present study, explored this subskill within the descriptors of synthesis subscale, but it was not explicitly scored as an individual factor. In the present study, the main researcher split them into two subskills to deeply examine the effect of IRT model on each subskill and to explore the contribution of each subskill of online research to the performance of communicate ideas responsibly. Such relation among the skills of online research was assumed by many researchers-but was not statistically investigated (e.g., Houth, 2017; Howard \& Davies, 2009). Subskill analysis of "communicate idea responsibly" showed great gain in the results of the experimental group, as compared to the results of the control group. Interestingly, the effect of the intervention on this subskill was very promising. Such findings are consistent with those noted in Chao et al. (2009), Lee et al. (2016), and Houth (2017) despite the little variations in measuring tools. Chao et al. (2009) experimented with two instructional practices within university context; however, one of these practices scaffolded students' learning through employing strategies of explicit teaching and modeling. Results showed positive relation between the instructional practice that provided more scaffolds to students' learning and the degree of plagiarism. Houth's (2017) results indicated a significant difference between pre-test and post-test scores as measured by Turnitin results as well as a research rubric which examined whether the "similarity reported by Turnitin report is plagiarism"(p. 73). Lee et al.'s (2016) results demonstrated similar gains in plagiarism reduction, where these researchers measured the level of plagiarism using a rubric and checked originality using an online platform. These researchers, among others, hypothesized that a decrease in copy-paste plagiarism would be attributed to providing effective instructions on online research skills and copy-paste avoidance. While Houth (2017) attributed the 
achievements in his study to providing instructions on all the skills of online research as one model in an interactive workshop, Lee et al. (2016) went further to highlight the significance of explicit instructions, scaffolding, and peer discussion while teaching these skills. They considered these strategies as critical to yield a decrease in copy-paste plagiarism. Such explanations could be applicable to the present study as well. Supported by existing literature, this would indicate that the knowledge students gained from the previous skills of "locate, evaluate, and synthesize" would have led to the development of communicate ideas responsibly, which measured the occurrences of copypaste trend. This would also indicate that using an online platform would have further supported and increased the speed of producing end references, considering today's students' interests in the use of online tools (Lee et al., 2016; Putman, 2013). Such findings imply that to address the phenomenon of copy-paste behavior, teachers must decrease preaching about academic integrity and, instead, embrace a systematic instructional practice that goes beyond focusing on individual scores of these skills to teaching these skills with in an interrelated model. Findings of present study, having similar results to those revealed in existing research in the field, would indicate the effectiveness of implementing such instructional practices of online research skills at lower grades such as Grade 8 , the context of the study, to help learners grow an ability that would change into a habit later.

Furthermore, it is critical to relate the results in the present study to existing literature in the context of Lebanon to examine them in light of such context and try to find common explanations. In general, to the knowledge of the authors of the present study, literature in Lebanon with regards to online research skills and copy-paste plagiarism was mostly descriptive in nature, except for the study conducted by Esseili (2019). The results of the present study supported those of Esseili's (2019) who intervened with a revised version of an existing program at a university level (Composition and Rhetoric Sequence program) to investigate the effect of this revised program on students' performance on online research skills and copy-paste trend. Having many strategies in common with IRT model used in the present study, the modified version of the program focused on (a) scaffolding assignments from simpler to more complex (e.g., narrative writing to review of literature writing); (b) involving participants as active learners; and (c) fostering peer modeling. Results indicated less occurrences of plagiarism where most students reported a denial of engaging in any plagiaristic behavior, attributing their responses to the environment of the class. It is worth noting that the results of the present study echoed the recommendations offered in some studies conducted in Lebanon whether at university level (Bacha \& Bahous, 2010) or at school level (of Fidaoui et al., 2010) regarding the effectiveness of explicit teaching and guidance. Most importantly, results of the present study have some promising implications for meeting the main goals set by Lebanon's National Educational Technology Strategic Plan, launched in 2012, which mandates that teachers, students, and principals should receive training on these skills.

At the theoretical level, findings from analyzing the research question reported in this paper supported the theoretical framework stated earlier as well. Firstly, they supported Bandura's looping process of observing, imitating, and modeling performance in the social context of the classroom (Social Learning Theory, 2014). They would also give credence to Vygotsky's views of the positive effect of peer modeling and scaffolding (Schunk, 2012), where ESL learners are met within their zone of proximal development (ZPD) as being guided and supported by teachers through breaking down instructions from simpler to more complex (e.g., phases of IRT). These findings also reflect the theory of new literacies which necessitates, as presented earlier, the existence of such a classroom environment for learning the complexities of online research skills.

\section{Recommendations for Future Research}

Although findings of the present study revealed significant development in online research skills and copy-paste avoidance, such results still indicate a need for future research. Overall, the present study revealed that the IRT model can be integrated within the Lebanese curriculum and its results could be generalized to private schools with similar characteristics. In the present study, traditional reading and comprehension scores were not accounted for due to the lack of standardized scores in Grade 8 in the context of Lebanon. Thus, further studies would be conducted in the first term of Grade10 where Grade 9 Lebanese official exams can be accounted for as standardized scores after making necessary modifications to the IRT lessons, test materials, and instruments to fit in the cognitive and knowledge demands of $10^{\text {th }}$ graders. One possible modification might comprise teaching the techniques for in-text citations, which Williamson and McGregor (2011) assumed as difficult for younger students who might be confused while adding in-text citations and writing ideas in their own words at the same time. It is worth noting that reviewed literature on studies conducted at middle school, whether they employed IRT (Castek, 2008; Kingsley, 2011) model or even employed any other instructional practice (Williamson \& McGregor, 2011), did not include the factor of in-text citations. Additionally, it is imperative that future studies gain insight into students' thinking through investigating their performance during small group discussions and independent inquiry using different qualitative methods to examine the extent of association between such factors and IRT implementation gain insights into students' thinking. Such studies might also investigate the effectiveness of structuring group work in a way where every student gets involved in practicing all strategies of the online research through reciprocal exchange of roles within the groups as suggested by Dwyer (2010). 
Finally, it is recommended that school personnel, such as principals, coordinators, and teachers, bring the topic of online research skills and copy-paste avoidance to the forefront of their discussions with an aim to consider what existing research has shown with regards to effective pedagogical benefits both for academic benefits at school and later at higher education. Such discussions would help schools better equip students with these skills before they reach tertiary levels through helping them grow an ability that would change into a habit later.

\section{Conclusions}

The findings revealed in this paper align with and further add to the body of existing research in the areas of online research skills and copy-paste avoidance. Improper reading and writing from online sources is an issue of concern to all academic levels, including middle schools. The findings of the present study revealed for middle school teachers many important conclusions. First, to address the problem of copy-paste, teachers must be aware that these skills need to be integrated into the teaching unit. Second, findings emphasized the significance of designing activities that scaffold students' learning from simpler to more complex ones, explicitly teaching the concept, and providing opportunities that build upon the effectiveness of peer discussion. Third, students' performance on online research skills should be measured using new tools such as the scoring rubrics used in the present study.

\section{References}

Ali, A. D. A. (2017). The effects of Internet reciprocal teaching on EFL students' new literacies of online

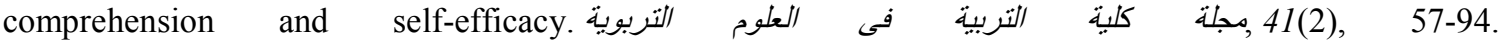
https://journals.ekb.eg/article_84150.html

Aryadoust, V. (Ed.), Raquel, M. (Eds.). (2019). Quantitative data analysis for language assessment volume I: Fundamental techniques. London: Routledge. https://doi-org.ezproxy.aub.edu.lb/10.4324/9781315187815

Awada, G., \& Diab, H. (2016). Lebanon's 2011 ICT education reform strategy and action plan: Curriculum success or abeyance. Cogent Education, 3(1), 1-14. http://doi.org/10.1080/2331186X.2016.1245086

Bacha, N. N., \& Bahous, R. (2010). Student and teacher perceptions of plagiarism in academic writing. Writing \& Pedagogy, 2(2), 251-280. http://doi .org/10.1558/wap.v2i2.251

Bacha, N. N., Bahous, R., \& Nabhani, M. (2012). High schoolers' views on academic integrity. Research Papers in Education, 27(3), 365-381. https://doi-org.ezproxy.aub.edu.lb/10.1080/02671522.2010.550010

Bandura, A. (1986). Social foundations of thought and action: A social cognitive theory. Englewood Cliffs, N.J.: Prentice-Hall.

Callahan, D. (2006). On Campus: Author Discusses the "Cheating Culture" With College Students. Plagiary: Cross - Disciplinary Studies in Plagiarism, Fabrication, and Falsification, 25 32. https://quod.lib.umich.edu/cgi/p/pod/dod-idx/on-campus-author-discusses-the-cheating-culture-withcollege.pdf? $=$ plag;idno $=5240451.0001 .004 ;$ format $=$ pdf

Castek, J. M. (2008). How do 4th and 5th grade students acquire the new literacies of online reading comprehension? Exploring the contexts that facilitate learning (Publication No. 3340875) [Doctoral Dissertations, University of Connecticut]. ProQuest Dissertations \& Theses Global. https://search-proquestcom.ezproxy.aub.edu.lb/docview/304629770?accountid=8555

Castek, J. (2017). Exploring the potential of Internet reciprocal teaching to improve online reading. In M. Kouider (Ed.), Improving reading comprehension (pp. 209-219), Rowman \& Littlefield.

Castek J., Coiro, J. Henry, L. A., Leu, D.J., \& Hartman D. (2015). Research on instruction and assessment in the new literacies of online research and comprehension. In S.R. Parris \& K.Headley (Eds.), From comprehension instruction: Research-based best practices (3rd ed., pp. 324-344). Location: Guildford Press

Çetin, M., \& Halisdemir, M. (2019). School administrators and generation Z students' perspectives for a better educational setting. Journal of Education and Training Studies, 7(2), 84-97. http://doi.org/10.11114/jets.v7i2.3773

Chao, C. A., Wilhelm, W. J., \& Neureuther, B. D. (2009). A study of electronic detection and pedagogical approaches for reducing plagiarism. The Journal of Research in Business Education, 51(1), 31. https://searchproquest-com.ezproxy.aub.edu.lb/docview/195588928? accountid=8555

Chen, H. (2010). Online reading comprehension strategies among fifth- and sixth-grade general and special education students. Education Research and Perspectives, 37(2), 79-109,134. https://search-proquestcom.ezproxy.aub.edu.lb/docview/1020696434? accountid $=8555$

Cho, H., Lai, C., \& Cumming, A. (2015, May 4). Writing from sources for academic purposes: A Synthesis of recent research. Paper presented at Symposium on Second Language Writing, University of Toronto, OISE. https://www.researchgate.net/publication/303971396_Writing_from_Sources_for_Academic_Purposes_A Synthesis_of_Recent_Research

Coiro, J. (2007). Exploring changes to reading comprehension on the internet: Paradoxes and possibilities for diverse adolescent readers (Publication No. 304864761) [Doctoral Dissertations, University of Connecticut]. ProQuest Dissertations and Theses Global. https://search-proquest- 
com.ezproxy.aub.edu.lb/docview/304864761?accountid=8555

Coiro, J., \& Dobler, E. (2007). Exploring the online reading comprehension strategies used by sixth - grade skilled readers to search for and locate information on the Internet. Reading Research Quarterly, 42(2), 214-257.

Coiro, J., \& Moore, D. W. (2012). New literacies and adolescent learners: An interview with Julie Coiro. Journal of Adolescent \& Adult Literacy, 55(6), 551-553.

Creswell, J. W., \& Plano, Clark. V. (2018). Designing and conducting mixed methods research (3rd ed.). Los Angeles: SAGE.

Cumming, A., Yang, L., Qiu, C., Zhang, L., Ji, X., Wang, J., \& Cao, R. (2018). Students' practices and abilities for writing from sources in English at universities in China. Journal of Second Language Writing, 39, 1-15. https://doi.org/10.1016/j.jslw.2017.11.001

Dwyer, B. (2010). Scaffolding internet reading: A study of a disadvantaged school community in Ireland (Publication No. U558597) [Doctoral dissertation, The University of Nottingham]. ProQuest Dissertations and Theses Global.. https:/search-proquestcom.ezproxy.aub.edu.lb/docview/1033192097?accountid=8555

Eagleton, M. B., \& Dobler, E. (2007). Reading the web: Strategies for Internet inquiry. New York: Guilford Press.

Esseili, F. (2019). Innovation in Writing Instruction: Towards Nurturing Confident, Motivated and Academically Honest L2 Writers. In Reinders H., Coombe C., Littlejohn A., Tafazoli D. (Eds), Innovation in language learning and teaching. New language learning and teaching environments. Palgrave Macmillan, Cham. https://doi.org/10.1007/978-3-030-13413-6_5

Evering, L. C., \& Moorman, G. (2012). Rethinking plagiarism in the digital age. Journal of Adolescent \& Adult Literacy, 56(1), 35-44. http://doi.org/10.1002/JAAL.00100

Fidaoui, D., Bahous, R., \& Bacha, N. N. (2010). CALL in Lebanese elementary ESL writing classrooms. Computer Assisted Language Learning, 23(2), 151-168. https://doi.org/10.1080/09588221003666248

Forzani, E., \& Leu, D. J. (2012). New literacies for new learners: The need for digital technologies in primary classrooms. The Educational Forum, 76(4), 421-424. Taylor \& Francis Group. https://doi.org/10.1080/00131725.2012.708623

Goldman, S. R., Braasch, J. L. G., Wiley, J., Graesser, A. C., \& Brodowinska, K. (2012). Comprehending and learning from internet sources: Processing patterns of better and poorer learners. Reading Research Quarterly, 47, 356-381. https://doi.org/10.1002/RRQ.027

Grabe, W., \& Zhang, C. (2013). Reading and writing together: A critical component of English for academic purposes teaching and learning. TESOL Journal, 4(1), 9-24. https://doi.org/10.1002/tesj.65

Graham, S. \& Harris, K. R. (2014). Conducting high quality writing intervention research: Twelve recommendations. Journal of Writing Research, 6(2), 89-123. https://www.jowr.org/Ccount/click.php?id=85

Graham, S., Liu, X., Aitken, A., Ng, C., Bartlett, B., Harris, K. R., \& Holzapfel, J. (2017). Effectiveness of literacy programs balancing reading and writing instruction: A meta - analysis. Reading Research Quarterly, 53(3), 279-304. https://doi-org.ezproxy.aub.edu.lb/10.1002/rrq.194

Hinton, P. R., Brownlow, C., McMurray, I., Cozens, B. (2004). SPSS explained. Routledge Taylor \& Francis Group: London and New York.

Houth, W. I. (2017). Information literacy: A comparative analysis of instructional treatment and plagiarism reduction (Publication No. 10933146) [Doctoral Dissertations, University of Phoenix]. ProQuest Dissertations \& Theses Global. https://search-proquestcom.ezproxy.aub.edu.lb/docview/2116175066?accountid $=8555$

Howard, R. M., \& Davies, L. J. (2009). Plagiarism in the Internet age. Educational Leadership, 66(6), 64-67.

Howard, R. M., Serviss, T., \& Rodrigue, T. K. (2010). Writing from sources, writing from sentences. Writing and Pedagogy, 2(2), 177-192.

Ismail, N., Kinchin, G., \& Edwards, J.-A. (2018). Pilot study, does it really matter? Learning lessons from conducting a pilot study for a qualitative $\mathrm{PhD}$ thesis. International Journal of Social Science Research, 6(1), 1-17. https://doi.org/ 10.5296/ijssr.v6i1.1172

Katz, R.B., Brynelson, N., Edlund, J. R (2013). Enacting Rhetorical Literacies: The Expository Reading and Writing Curriculum in Theory and Practice. In R.B. Ruddell \& N.J. Unrau (Eds.), Theoretical models and the processes of reading (6th ed., pp.978-1014). Newark, DE: International Reading Association. http:// doi.org/10.1598/0872075028.35

Kingsley, T. L. (2011). Integrating new literacy instruction to support online reading comprehension: An examination of online literacy performance in 5th grade classrooms (Publication No. 3466808). [Doctoral Dissertations, Ball State University]. ProQuest Dissertations Publishing. https://search-proquestcom.ezproxy.aub.edu.lb/docview/885864258?accountid=8555

Koo, T. K., \& Li, M. Y. (2016). A guideline of selecting and reporting intraclass correlation coefficients for reliability research. Journal of Chiropractic $155-163$. http://doi.org/10.1016/j.jcm.2016.02.012 
Lee, C. W. Y., Chu, S. K. W., Cheng, J. O. Y., \& Reynolds, R. (2016). Plagiarism - free inquiry project - based learning with UPCC pedagogy. Proceedings of the Association for Information Science and Technology, 53(1), 1-11. https://doi-org.ezproxy.aub.edu.lb/10.1002/pra2.2016.14505301033

Leu, D. J., Castek, J., Hartman, D., Coiro, J., Henry, L., Lyver, S. (2005). Evaluating the development of scientific knowledge and new forms of reading comprehension during online learning. Final report presented to the North Central Regional Educational Laboratory/ Learning Point Associates. https://newliteracies.uconn.edu/wp-content/uploads/sites/448/2014/07/FinalNCRELReport.pdf

Leu, D. J., Jr., Kinzer, C. K., Coiro, J., \& Cammack, D. (2004). Toward a theory of new literacies emerging from the Internet and other ICT. In R. B. Ruddell \& N. Unrau (Eds.), Theoretical models and processes of reading (5th ed., pp. 1568-1611). Newark, DE: International Reading Association.

Leu, D.J., Zawilinski, L., Forzani, E., \& Timbrell, N. (2014). Best practices in new literacies and the new literacies of online research and comprehension. In L.M. Morrow \& L.B. Gambrell (Eds.), Best practices in literacy instruction (5th ed., pp. 343-364). New York, NY: Guilford.

Malloy, J., Castek, J., \& Leu, D. J.(2010-2014). Silent reading and online reading comprehension. In E. H. Hiebert \& R. Reutzel. Revisiting Silent Reading: New Directions for Teachers and Researchers (pp. 221-240). Newark, DE: International Reading Association.

McCabe, D. L., Feghali, T., \& Abdallah, H. (2008). Academic dishonesty in the middle east: Individual and contextual factors. Research in Higher Education, 49(5), 451-467. https://doi.org/10.1007/s11162-008-90929

Ministry of Education and Higher Education (2012). Teaching and learning in the digital age: Lebanon's national educational technology strategic Plan. Beirut, Lebanon: The Ministry of Education and Higher Education Strategic Planning Development Team. http://www.mehe.gov.lb/Uploads/file/TLSP.pdf

Palinscar, A. S., \& Brown, A. L. (1984). Reciprocal teaching of comprehension-fostering and comprehensionmonitoring activities. Cognition and Instruction, 1(2), 117-175. http://doi:10.1207/s1532690xci0102_1

Pallant, J. (2011). SPSS Survival manual. A step by step guide to data analysis using SPSS (4th ed.). Crown Nest, Australia : Allen \& Unwin.

Pecorari, D., \& Petrić, B. (2014). Plagiarism in second-language writing. Language Teaching, 47(03), 269302.http:// doi.org/10.1017/S0261444814000056.

Putman, S. M. (2013). Exploring dispositions toward online reading: Analyzing the survey of online reading attitudes and behaviors. Reading Psychology, 35(1), 1-31. https://doiorg.ezproxy.aub.edu.lb/10.1080/02702711.2012.664250

Rothschild. D. (2009, September 15). A new generation of plagiarism. iThenticate. $\quad \mathrm{http}: / / \mathrm{www}$.ithenticate.com/plagiarism-detection-blog/bid/53170/A-New-Generation-ofPlagiarism\#.XdCaGVczbIU

Robbins, K. R. (2010). Online reading comprehension among seventh grade students with high incidence disabilities in inclusive settings: A mixed methods study (Publication No. 3439377) [Doctoral Dissertations, Clemson University]. ProQuest Dissertations Publishing. https://search-proquestcom.ezproxy.aub.edu.lb/docview/850523793?accountid=8555

Schunk, D. H. (2012). Learning Theories: An Educational Perspective (6th ed.). Boston: Pearson.

Schwartz, K. (2016, October 16). Strategies to help students 'go deep' when reading digitally. KQED. https://www.kqed.org/mindshift/46426/strategies-to-help-students-go-deep-when-reading-digitally

Sisti, D. A. (2007). How do high school students justify internet plagiarism? Ethics \& Behavior, 17(3), $215-231$. https://doi.org/10.1080/10508420701519163

Smith, S. W., Daunic, A. P., \& Taylor, G. G. (2007). Treatment fidelity in applied educational research: Expanding the adoption and application of measures to ensure evidence-based practice. Education and Treatment of Children, 30(4), 121-134. http://doi.org/10.1353/etc.2007.0033

Social Learning Theory. (2014). http://www.learning-theories.com/social-learning- theorybandura.htm

Solomon, G. (2018, August). Why mastering writing skills can help future-proof your career. Forbes. https://www.forbes.com/sites/gretasolomon/2018/08/09/why-mastering-writing-skills-can-help-futureproof-your-career/\#4962f92c5831

Vygotskŭ1, L. S. (1978). Mind in society: The development of higher psychological processes. Cambridge: Harvard University Press.

Williamson, K., \& McGregor, J. (2011). Generating knowledge and avoiding plagiarism: Smart information use by high school students. School Library Media Research SLMR, 14, 1-22. https://search-proquestcom.ezproxy.aub.edu.lb/docview/2395507397?accountid $=8555$ 


\begin{abstract}
About Author 1:
Mrs. Hoda Kain graduated from the Lebanese International University in 2011 with a Master's degree in TEFL and from the Lebanese University in 1994 with a BA in English literature. She has an extensive experience as a high school ESL teacher and project -based learning trainer. She taught courses related to educational technology and methods of teaching English at Jinan University, Saida- Lebanon. Her research interests include Information Technology tools, Web 2.0 tools, online research skills, and conceptual-based learning. She is a certified teacher from the University of Oregon for online-based courses, mainly in Webskills, English for Specific purposes, and critical thinking. Currently, she is a CAS coordinator in the International Baccalaureate program at the school she teaches at. She has recently fulfilled the requirements of the PHD program at Saint-Joseph University of Beirut.
\end{abstract}

About Author 2

Dr. Nehme Safa is an associate professor at Saint Joseph University of Beirut, Faculty of Educational Sciences. $\mathrm{He}$ is responsible for carrying out research projects at the Educational Research Laboratory, Faculty of Educational Sciences. Dr. Safa teaches courses at the graduate level and gives seminars at the post graduate level. 